\title{
Establishment of an Experimental System for Intraperitoneal Chemotherapy in a Rat Model
}

\author{
SUNWOO PARK ${ }^{1 * \dagger}$, SOO JIN PARK ${ }^{2 * \dagger}$, HEE SU LEE ${ }^{3 \dagger}$, JIYEON HAM $^{1 \dagger}$, EUN JI LEE ${ }^{2 \dagger}$, \\ JUNSIK KIM ${ }^{3 \dagger}$, SOOMIN RYU ${ }^{1}$, AERAN SEOL ${ }^{2}$, WHASUN LIM ${ }^{4 \dagger}$, JUNG CHAN LEE ${ }^{5,6 \dagger}$, \\ GWONHWA SONG ${ }^{1 \dagger}$ and HEE SEUNG KIM ${ }^{2 \dagger}$; On Behalf of the KoRIA ${ }^{\dagger}$ Trial Group \\ ${ }^{1}$ Institute of Animal Molecular Biotechnology and Department of Biotechnology, \\ College of Life Sciences and Biotechnology, Korea University, Seoul, Republic of Korea; \\ ${ }^{2}$ Department of Obstetrics and Gynecology, Seoul National University College of Medicine, Seoul, Republic of Korea; \\ ${ }^{3}$ Interdisciplinary Program in Bioengineering, Seoul National University Graduate School, Seoul, Republic of Korea; \\ ${ }^{4}$ Department of Food and Nutrition, Kookmin University, Seoul, Republic of Korea; \\ ${ }^{5}$ Department of Biomedical Engineering, Seoul National University College of Medicine, Seoul, Republic of Korea; \\ ${ }^{6}$ Institute of Medical and Biological Engineering, Medical Research Center, \\ Seoul National University, Seoul, Republic of Korea
}

\begin{abstract}
Aim: To establish an experimental system for comparing different methods of intraperitoneal chemotherapy in a rat model. Materials and Methods: We used six-week-old Sprague-Dawley rats, and created an early postoperative intraperitoneal chemotherapy (EPIC) system using 18-gauge syringes and evacuators, and a hyperthermic intraperitoneal chemotherapy (HIPEC) system using two peristaltic pumps which controlled the flow rate and temperature. Pressurized intraperitoneal aerosol chemotherapy (PIPAC) was achieved using a nozzle for dispersing aerosols at a flow rate up to 41.5 $\mathrm{ml} / \mathrm{min}$. The distribution and intensity of $0.2 \%$ trypan blue dye was compared among three methods. Results: The distribution was limited and the intensity was weak after EPIC, and the dye stained moderately in gravity-dependent regions after
\end{abstract}

This article is freely accessible online.

*These Authors contributed equally to this article.

\footnotetext{
$\dagger$ Authors are included in the KoRIA (KOrean Rotational Intraperitoneal pressurized Aerosol chemotherapy) trial group

Correspondence to: Gwonhwa Song, Ph.D., Institute of Animal Molecular Biotechnology and Department of Biotechnology, College of Life Sciences and Biotechnology, Korea University, 145 Anam-ro, Seongbuk-gu, Seoul 02841, Republic of Korea. E-mail: ghsong@korea.ac.kr and Hee Seung Kim, MD, Ph.D., Department of Obstetrics and Gynecology, Seoul National University College of Medicine, 101 Daehak-Ro Jongno-Gu, Seoul 03080, Republic of Korea. E-mail: bboddi0311@gmail.com
}

Key Words: Experimental system, intraperitoneal chemotherapy, rat.
HIPEC. On the other hand, the distribution was the most comprehensive, and the intensity was the greatest after PIPAC. Conclusion: This experimental system in a rat model may reflect the comparative effect among EPIC, HIPEC and PIPAC in humans.

Peritoneal metastasis (PM) represents disseminated and growing tumors on the peritoneal surface found in advanced or recurrent diseases with solid tumors (1). PM is found in $10-35 \%$ of patients with gastro-intestinal cancer, and in up to $50 \%$ of those with ovarian cancer $(2,3)$. Although various types of anticancer drugs for intravenous chemotherapy have been introduced to treat patients with peritoneal carcinomatosis, they still have poor prognosis, with median survival of less than 20 months (4). Intraperitoneal chemotherapy has been used as an option for overcoming drug resistance developed after intravenous chemotherapy because intraperitoneal chemotherapy acts via direct diffusion of drugs into tumors in the peritoneal cavity (5).

As the first-generation method of intraperitoneal chemotherapy, early postoperative intraperitoneal chemotherapy (EPIC) has been reported to improve survival in patients with colonic (6), and ovarian (7) cancer. However, an increase of chemotherapy-induced toxicity by the direct diffusion of drugs may not allow completion of a sufficient number of cycles of chemotherapy, and this may reduce survival. As a secondgeneration method, hyperthermic intraperitoneal chemotherapy (HIPEC) utilizes hyperthermia of $40-43^{\circ} \mathrm{C}$ and $30 \%$ of the dose of anticancer drugs used for intravenous chemotherapy (5). HIPEC is emerging as a new medical technology for improving survival because its addition to cytoreductive surgery was shown to improve survival compared with cytoreductive 
surgery alone in patients with ovarian cancer who received neoadjuvant chemotherapy (8). However, HIPEC requires careful attention because it is associated with renal or hepatic dysfunction in up to $23 \%$ of cases and treatment-related death by hyperthermia and drug-induced toxicity in up to $7 \%$ (9).

As a third-generation method, pressurized intraperitoneal aerosol chemotherapy (PIPAC) deliver anticancer drugs to the peritoneum in the form of aerosols under an abdominal pressure of $12 \mathrm{mmHg}$ (10). It has some advantages such as a very low dose-equivalent, about $1 \%$ dose of anticancer drugs used for intravenous chemotherapy, and normothermia, which reduce treatment-related toxicity remarkably $(11,12)$. Although phase II trials showed the effect and safety of PIPAC in treating solid tumors, it has some disadvantages, including limited use of drugs including doxorubicin and cisplatin $(13,14)$.

Although these three methods of intraperitoneal chemotherapy are promising for treating patients with PM, there are few research studies on the most suitable conditions for performing intraperitoneal chemotherapy. For investigating the most appropriate methods and conditions of intraperitoneal chemotherapy, their utilisation in animal models is important because the effects can he compared among different methods and parameters of intraperitoneal chemotherapy. In this study, we established an experimental system using rats for comparing effect among EPIC, HIPEC and PIPAC.

\section{Materials and Methods}

Selection of animals. Six-week-old female Sprague-Dawley rats (weighing from 160 to $180 \mathrm{~g}$ ) were purchased from DBL (Chungcheong-do, Korea) and were allowed to acclimate for 1 week before the experiment. Two rats were used for EPIC, one for HIPEC and two for PIPAC. Rats were maintained with standard chow and housed under 12-h light on/off cycle. The animals were euthanized at the end of the experiments and immediately autopsied. This experiment was performed with ethical approval by Korea University (KUIACUC-2019-0055).

EPIC setup. An 18-gauge syringe and an evacuator were introduced into each side of the peritoneal cavity, and designed so that releasing the clamp of the evacuator ejected the solution $30 \mathrm{~min}$ after its injection.

HIPEC setup. Two peristaltic pumps were included in a HIPEC device. A pump served to deliver trypan blue from the drug reservoir to the peritoneal cavity of the animal while another was responsible for the return of the drug from the peritoneal cavity to the drug reservoir. Two stepper motors were used to drive the pumps. Tygon tubing (1.59 mm ID, $3.18 \mathrm{~mm}$ OD, Saint-Gobain Performance Plastics Co., Akron, OH, USA) was used as circuit lines. Intravenous catheters were connected to each end of the lines responsible for the inflow and outflow. The opposite ends of the lines were connected to the drug reservoir. A saline bag was used as the drug reservoir and was placed in a temperature-controlled water bath. All tube connections were secured using Luer Lock
Fittings (1/16" barb; KENT Systems, LLC., Loveland, CO, USA). An infrared thermometer was attached to the inflow line. Arduino Uno board was used to control the flow rate of the pumps and process the signals obtained from the thermometer. The flow rates for both inflow and outflow were synchronously controlled up to $7.5 \mathrm{ml} / \mathrm{min}$. The flow rate $(\mathrm{ml} / \mathrm{min})$ and temperature $\left({ }^{\circ} \mathrm{C}\right)$ were displayed via a $16 \times 2$ character dot-matrix LCD module.

PIPAC setup. A peristaltic pump was used to deliver trypan blue from the reservoir to the peritoneal cavity of the animal at a flow rate up to $41.5 \mathrm{ml} / \mathrm{min}$. A stepper motor was used to drive the pump. A full cone spray nozzle (orifice diameter $0.8 \mathrm{~mm}$; ISN, Republic of Korea) was selected for its ability to disperse drug droplets evenly and appropriately for the oval shape of the peritoneal cavity and a wide range of spray angles (maximum $40^{\circ}$ ). The spray angle was considered suitable for the low flow rate, less than $15 \mathrm{ml} / \mathrm{min}$, for small-sized animals. The nozzle was connected to a 1/4-inch tube fitting, which was then plugged into a Teflon tube (1/4-inch; KITZ, Republic of Korea). Teflon tubing was selected for its stiffness to endure the pressure that Tygon tubing cannot provide. The opposite end of the Tygon tube was connected to a drug reservoir, which was made using a saline bag. All tube lines were secured with Luer Lock fittings. A pressure sensor (MS5412; TE Connectivity Ltd., Schaffhausen, Switzerland) was installed to monitor the pressure in the peritoneal cavity with $\mathrm{CO}_{2}$ being supplied. A three-way stopcock

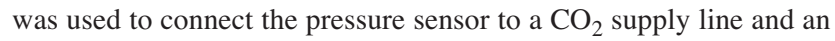
intravenous catheter (BD Angiocath Plus; Becton, Dickinson and Company, NJ, USA). Arduino Uno board was used to control the flow rate of the pump and to present the flow rate $(\mathrm{ml} / \mathrm{min})$ and abdominal pressure $(\mathrm{mmHg})$ values via a $16 \times 2$ character dot-matrix LCD module.

Measurements. Before intraperitoneal chemotherapy, SpragueDawley rats were anesthetized with $350 \mu \mathrm{l}$ of a mixture of ketamine (100 mg/kg; Yuhan Corporation, Seoul, Republic of Korea) and Rompun ${ }^{\circledR}$ Inj. (10 mg/kg; Bayer, Suwon, Republic of Korea). Thereafter, equal volumes of $0.4 \%$ trypan blue dye (Sigma-Aldrich, St. Louis, MO, USA) and $0.9 \% \mathrm{NaCl}$ were mixed, and injected into the peritoneal cavity during intraperitoneal chemotherapy for 30 $\min$.

For EPIC, $50 \mathrm{ml}$ of $0.2 \%$ trypan blue dye was injected into the peritoneal cavity of two rats for $30 \mathrm{~min}$ at room temperature of $22^{\circ} \mathrm{C}$ as shown in Supplementary Video S1. For HIPEC, $50 \mathrm{ml}$ of $0.2 \%$ trypan blue dye was injected into the peritoneal cavity of two rats for $30 \mathrm{~min}(1.53 \pm 2 \mathrm{ml} / \mathrm{min})$ as shown in Supplementary Video S2. The temperature of the water bath and inflow catheter was $52^{\circ} \mathrm{C}$ and $41-42^{\circ} \mathrm{C}$, respectively (Figure 1). For PIPAC, $\mathrm{CO} 2$ was injected into the peritoneal cavity of two rats through BD Angiocath Plus (BD, Singapore) generating $3 \pm 1 \mathrm{mmHg}$ pressure in the peritoneal cavity. Thereafter, $50 \mathrm{ml}$ of $0.2 \%$ trypan blue dye was dispersed through a nebulizer for $4 \mathrm{~min}$ at a room temperature of $22^{\circ} \mathrm{C}$, and then the pressure was maintained for 30 min with a flow rate of 13.47 $\mathrm{ml} / \mathrm{min}$ (Figure 2 and Supplementary Video S3). After $30 \mathrm{~min}$, the dye was drained using the evacuator (Sewoon Medical Co., Ltd). The overall settings for each type of intraperitoneal chemotherapy are summarized in Table I.

After completion of the treatment, the peritoneum and gastrointestinal tract were washed with $50 \mathrm{ml}$ of $0.9 \% \mathrm{NaCl}$ for all rats. The abdomen of each rat was then opened immediately to evaluate the distribution and intensity of $0.2 \%$ trypan blue dye 
A

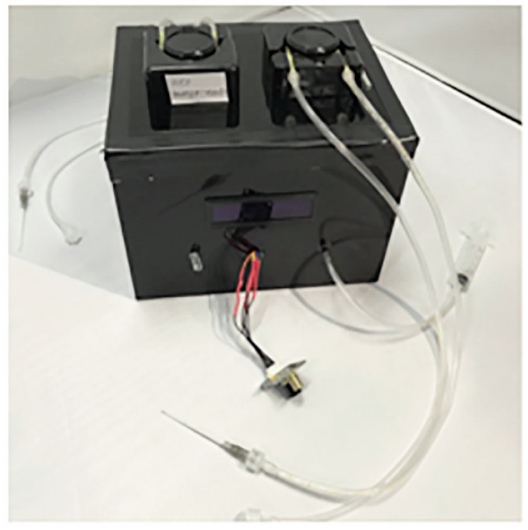

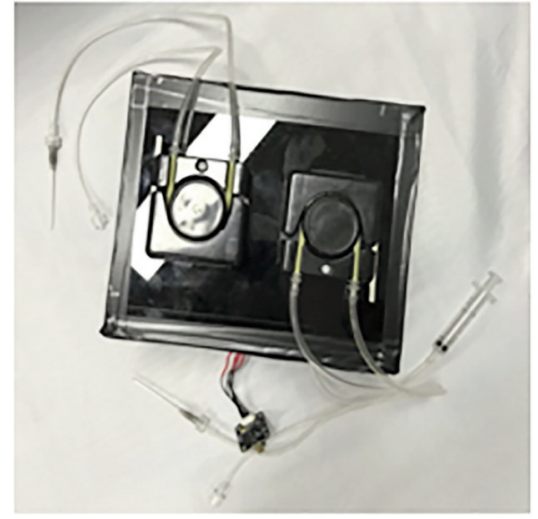

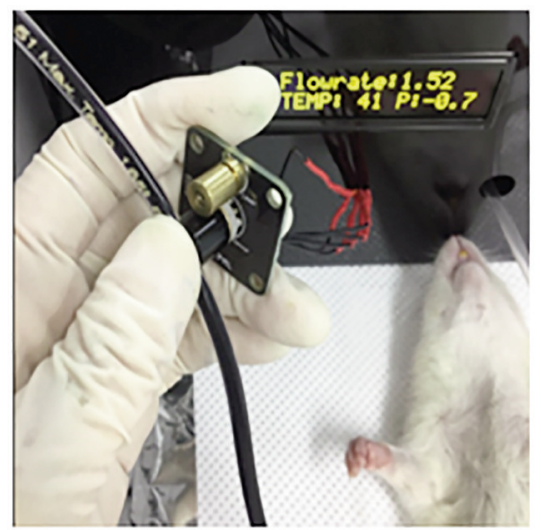

B

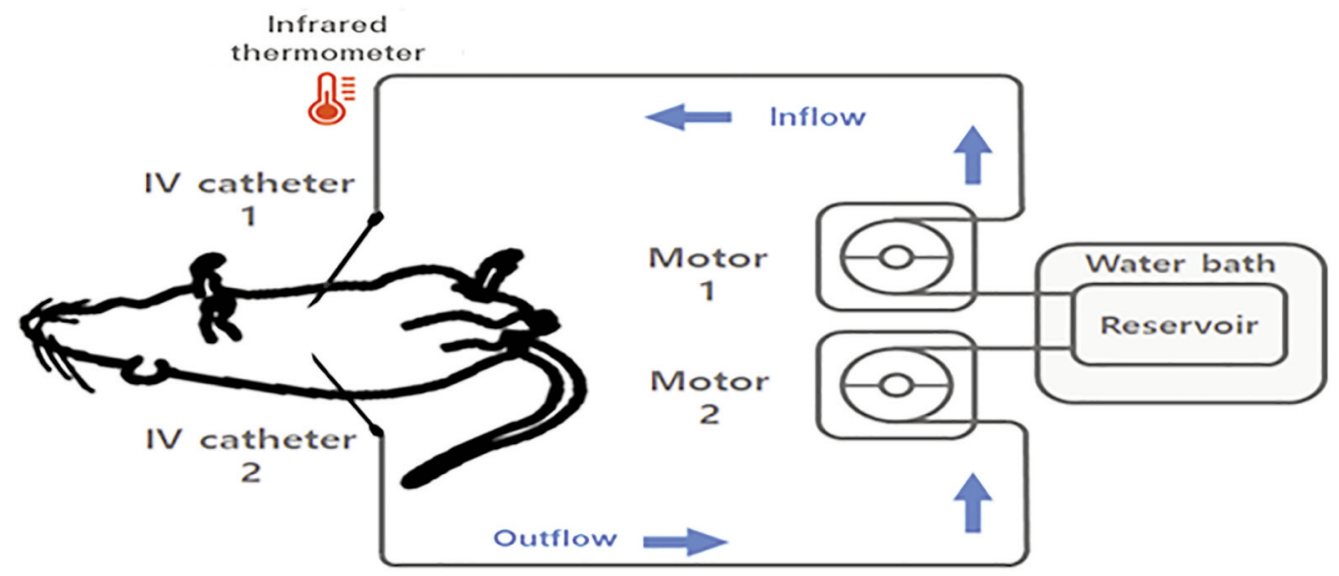

Figure 1. Equipment for hyperthermic intraperitoneal chemotherapy (HIPEC) in a rat model. A: The device with two stepper motors, an infrared thermometer, and a 16×2 character dot-matrix LCD module. B: Schematic diagram of the experimental setup for HIPEC, during which the flow rate was $1.53 \mathrm{ml} / \mathrm{min}$ and the inflow temperature was $41-42^{\circ} \mathrm{C}$. IV: Intravenous.

staining. The naked eye staining of parietal (peritoneum) and visceral organs (small and large bowels) of rats was compared under EPIC, HIPEC and PIPAC. After the evaluation, the abdominal wall was closed with 4-0 surgifit suture, and the skin with 3-0 black silk. Thereafter, we checked for any side-effects and health of the rats after the surgery daily for 10 days.

\section{Results}

When we compared the distribution and intensity of $0.2 \%$ trypan blue dye staining among EPIC, HIPEC and PIPAC, the distribution was limited and the intensity was weak after EPIC, whilst the dye moderately stained gravity-dependent regions of the visceral and parietal organs after HIPEC. On the other hand, the distribution was the most comprehensive without depending on gravity, and the intensity was the greatest in the visceral and parietal organs after PIPAC (Figure 3). All rats survived well for 10 days after EPIC, HIPEC and PIPAC.
Table I. Comparison of the experimental setup for early postoperative intraperitoneal chemotherapy (EPIC), hyperthermic intraperitoneal chemotherapy (HIPEC) and pressurized intraperitoneal aerosol chemotherapy (PIPAC) using a 1:1 volume ratio of $0.4 \%$ trypan blue: $0.9 \% \mathrm{NaCl}$.

\begin{tabular}{lccc}
\hline Type & EPIC & HIPEC & PIPAC \\
\hline Total volume, $\mathrm{ml}$ & 50 & 50 & 50 \\
Temperature, ${ }^{\circ} \mathrm{C}$ & Room: 22 & $\begin{array}{c}\text { Water-bath: 52 } \\
\text { Inflow catheter: 41-42 }\end{array}$ & Room: 22 \\
Flow rate, $\mathrm{ml} / \mathrm{min}$ & 50 & 1.53 & 13.47 \\
Pressure, $\mathrm{mmHg}$ & - & - & 3 \\
No. of catheters & 2 & 2 & 3 \\
\hline
\end{tabular}

\section{Discussion}

Many relevant studies using small animals for evaluating the effect of different methods of intraperitoneal chemotherapy have been reported (Table II) (15-35). However, only one or 

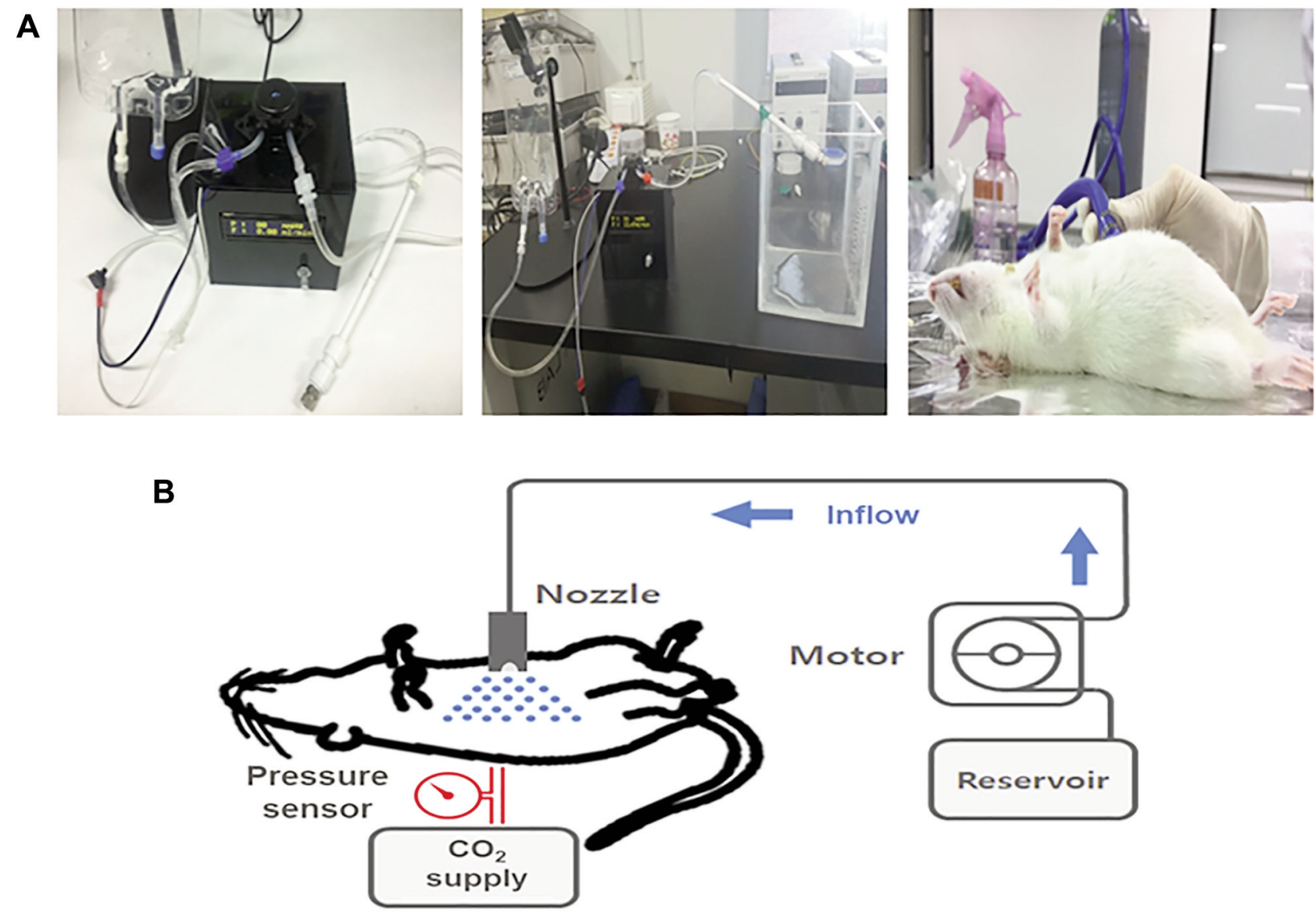

Figure 2. Equipment for pressurized intraperitoneal aerosol chemotherapy (PIPAC) in a rat model. A: The device with a peristaltic pump, a pressure sensor, and a full cone spray nozzle. B: Schematic diagram of the experimental setup for PIPAC, during which CO $\mathrm{O}_{2}$ was injected into the peritoneal cavity, and the flow rate and pressure in the peritoneal cavity were maintained at $13.47 \mathrm{ml} / \mathrm{min}$ and $3 \mathrm{mmHg}$ at room temperature $\left(22^{\circ} \mathrm{C}\right)$ for $30 \mathrm{~min}$.

two methods of intraperitoneal chemotherapy have been utilized in most studies, and experimental conditions including temperature differ among them. In this study, we established an experimental system for comparing the effect among three types of intraperitoneal chemotherapy in a rat model, suggesting this may reflect the comparative effects among EPIC, HIPEC and PIPAC in humans.

This experimental system enables us to evaluate how modulation of experimental conditions can affect the efficacy of each intraperitoneal chemotherapy. For example, PIPAC reportedly achieves greater penetration of drugs than EPIC (36); deeper penetration by PIPAC is expected to have greater tumoricidal activity during the same cycles of intraperitoneal chemotherapy but experimental evidence for this is still needed. Moreover, the control of abdominal temperature or pressure has been suggested to change the effect during intraperitoneal chemotherapy in previous studies using cancer cell lines $(37,38)$. Thus, the effects of modulating experimental conditions can be demonstrated in this experimental system using rats.

Synergistic effects achieved by combining the advantages of each method of intraperitoneal chemotherapy can also be investigated in this experimental system. HIPEC has two main pharmacokinetic problems, namely limited penetration into the peritoneum and limited distribution, whereas PIPAC lacks the advantage of hyperthermia. For overcoming these disadvantages of each method, the concept of hyperthermic PIPAC was introduced in a porcine model (39). Thus, the synergistic effect of hyperthermic PIPAC can be demonstrated by comparing effects among these different methods of intraperitoneal chemotherapy in this experimental system using rat models with PM.

Moreover, the safety of intraperitoneal chemotherapy can also be evaluated in this experimental system. Data on the maximal dose of drugs and temperature to ensure the safety of EPIC or HIPEC are lacking. Surgery is considered a 

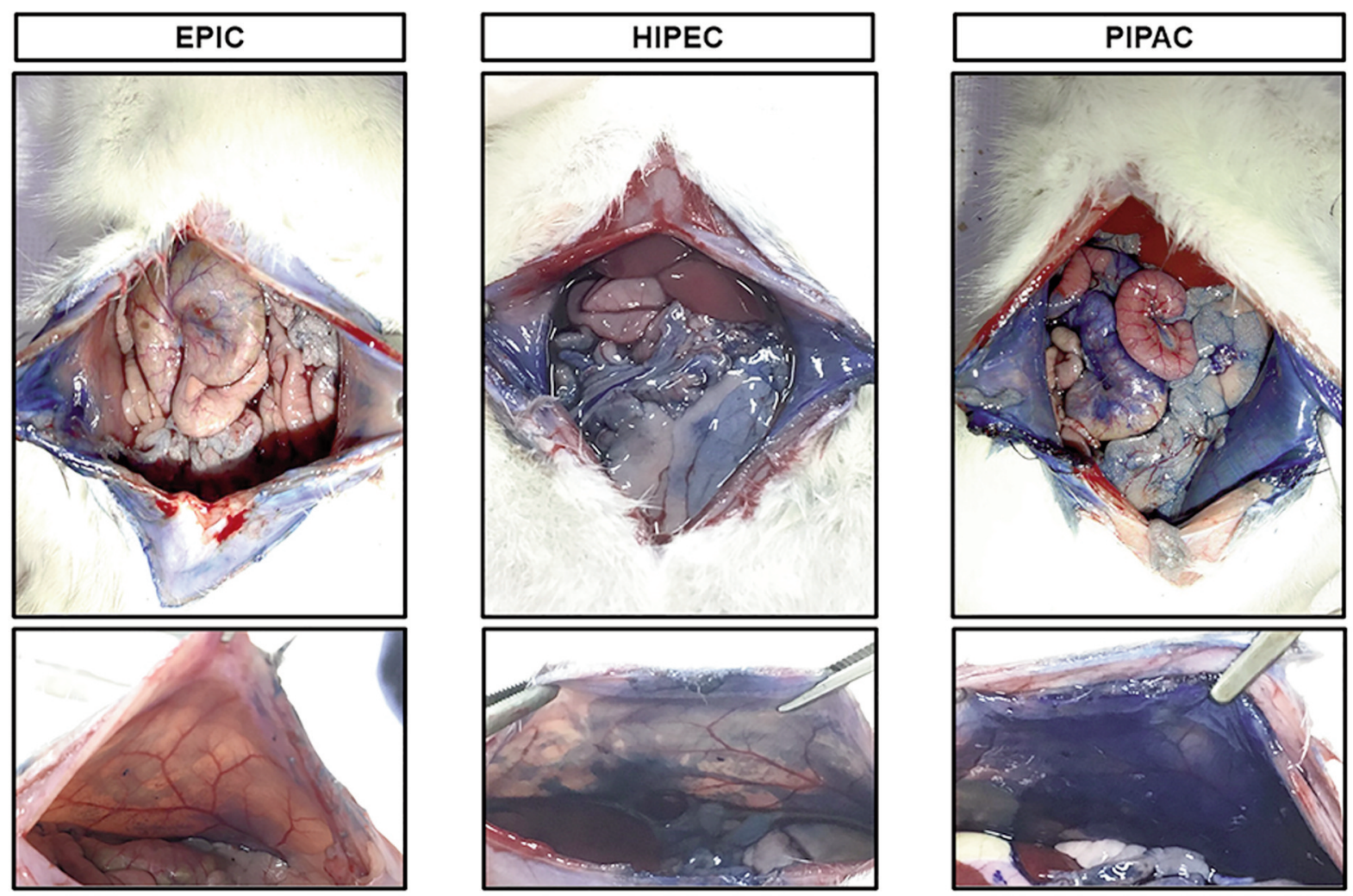

Figure 3. Comparison of the distribution and intensity of $0.2 \%$ trypan blue dye in the visceral organs (upper panel) and the parietal organ (lower panel) after early postoperative intraperitoneal chemotherapy (EPIC), hyperthermic intraperitoneal chemotherapy (HIPEC) and pressurized intraperitoneal aerosol chemotherapy (PIPAC).

Table II. Previous intraperitoneal chemotherapy studies in small animals.

\begin{tabular}{|c|c|c|c|c|}
\hline Species & Type & Operative time ( $\mathrm{min}$ ) & Temperature $\left({ }^{\circ} \mathrm{C}\right)$ & References \\
\hline Sprague-Dawley Rat & EPIC & 90 & $32.5-37$ & $15-17$ \\
\hline Sprague-Dawley rat & HIPEC & 90 & $40-42.5$ & $15-17$ \\
\hline Sprague-Dawley rat & EPIC & 60 & 36.4 & 18 \\
\hline Sprague-Dawley rat & HIPEC & 60 & 42.5 & 18 \\
\hline Sprague-Dawley rat & EPIC & 25 & 37 & 19 \\
\hline Sprague-Dawley rat & HIPEC & 25 & 40,43 & 19 \\
\hline WAG/Rij rat & EPIC & 90 & 37 & 20 \\
\hline WAG/Rij rat & HIPEC & 90 & $40-42$ & $20-23$ \\
\hline WAG/Rij rat & HIPEC & 60 & $39-43.2$ & 24,25 \\
\hline WAG/Rij rat & EPIC & 45 & 37 & 26 \\
\hline WAG/Rij rat & HIPEC & 45 & 41 & 26 \\
\hline BDIX rat & HIPEC & 60 & $41.2-42.3$ & 27,28 \\
\hline Wistar rat & EPIC & 60 and 90 & $18-23$ & 29 \\
\hline Wistar rat & HIPEC & 60 and 90 & 42 & 29 \\
\hline Wistar rat & HIPEC & 45 & $40.5-41.5$ & 30 \\
\hline Athymic nude rat & HIPEC & 60 & $41-42.5$ & 31,32 \\
\hline Athymic nude rat & HIPEC & 45 & 41.5 & 33 \\
\hline C57BL/6, Mouse & HIPEC & 12 & 43 & 34 \\
\hline Athymic nude rat & PIPAC & 30 & 37 & 35 \\
\hline
\end{tabular}

EPIC: Early postoperative intraperitoneal chemotherapy; HIPEC: hyperthermic intraperitoneal chemotherapy; PIPAC: pressurized intraperitoneal aerosol chemotherapy. 
relative contraindication before PIPAC because a case of postoperative bowel perforation after surgery followed by PIPAC was reported (40). Although postoperative bowel perforation has been suggested to develop due to high concentration of drugs in tissues at the anastomosis site hindering wound healing, there are no further basic and clinical evidence as to why PIPAC cannot be performed immediately after surgery like HIPEC. Thus, we believe that this hypothesis can be investigated via this experimental system, using rats which underwent surgery before PIPAC.

In particular, a model using rats with peritoneal carcinomatosis is more realistic for evaluating the effect of intraperitoneal chemotherapy in this experimental system. Xenograft models using athymic mice or Fischer 344 rats have been reported $(35,41,42)$, in which SKOV-3 Luc IP2 or NuTu-19 cells were injected intraperitoneally. Although xenograft models using nude mice are easy to develop, we were unable to equip the device of PIPAC in mice because the nozzle was too large to be inserted into the peritoneal cavity. Furthermore, capnoperitoneum was formed too quickly and $\mathrm{CO}_{2}$ in the peritoneal cavity was also released too quickly due to the very small volume of the peritoneal cavity of the mice. Considering that rats are more tolerant of repetitive procedures than mice because the wound is relatively small for inserting the devices for intraperitoneal chemotherapy (35), we believe that this experimental system using rats is more appropriate for investigating the effect and safety of intraperitoneal chemotherapy. Furthermore, this experimental system using rats has an additional advantage that repetitive treatments are possible because most of the rats were healthy after intraperitoneal chemotherapy, as in a previous study (35)

However, this experimental system has some limitations as follows. Firstly, the size of aerosols during PIPAC was not measured in this experimental system. However, aerosols were injected at a flow rate of $13.47 \mathrm{ml} / \mathrm{min}$, half of the value used in a previous study $(0.5 \mathrm{ml} / \mathrm{s})$, with maintenance of the pressure of capnoperitoneum in rats. Furthermore, PIPAC showed strong staining by $0.2 \%$ trypan blue dye in both the parietal and visceral organs similar to a previous study (35). Ex vivo or preclinical studies using porcine models showed that the depth of penetration of doxorubicin depended on the amount of doxorubicin distributed $(43,44)$, which suggests that the sizes of aerosols may not be important in increasing the depth of penetration in rats because most aerosols are well distributed, unlike swine models with their relatively large peritoneal cavity. Secondly, we did not validate this experimental system using rats with peritoneal carcinomatosis This validation should be conducted in rats with peritoneal carcinomatosis from different types of tumor cells, considering the change of the dose of drugs used in the human body to that used in rats (45).
Although different types of intraperitoneal chemotherapy are used in the clinical setting, we found no evidence of the most appropriate method for patients with peritoneal carcinomatosis. Thus, this experimental system enables us comparison of the effect and safety among these three types of intraperitoneal chemotherapy in rats, and may be helpful in selecting the most appropriate method by modulating experimental conditions such as temperature.

\section{Conflicts of Interest}

The Authors declare no competing interests.

\section{Authors' Contributions}

HSK and GS conceived the study. SP, HSL, JK, JH, SR, EJL, SJP, SO, and AS performed the experiments. WL and JCL analyzed the data. SP, SJP, HSK and GS drew the figures, and wrote the article. All Authors read and approved the final article.

\section{Acknowledgements}

The Authors express their deep appreciation to Dalim Medical Corp. and Samyang Biopharmaceuticals Corp. for collaborative work.

This research was supported by grants from Seoul National University [Grant numbers, 800-20170249, 800-20180201, 80020190437], and Seoul National University Hospital [Grant number 06-20173250].

Supplementary video 1. Early postoperative intraperitoneal chemotherapy in a rat model (available at: https://youtu.be/Ukizu hUJFv8).

Supplementary video 2. Hyperthermic intraperitoneal chemotherapy in a rat model (available at: https://youtu.be/dxjySW BgRU4).

Supplementary video 3. Pressurized intraperitoneal aerosol chemotherapy in a rat model (available at: https://youtu.be/-Xi2F7i1 GDY).

\section{References}

1 Jayne DG, Fook S, Loi C and Seow-Choen F: Peritoneal carcinomatosis from colorectal cancer. Br J Surg 89(12): 1545-1550, 2002. PMID: 12445064. DOI: 10.1046/j.1365-2168.2002.02274.x

2 Pelz JO, Vetterlein M, Grimmig T, Kerscher AG, Moll E, Lazariotou M, Matthes N, Faber M, Germer CT, Waaga-Gasser $\mathrm{AM}$ and Gasser M: Hyperthermic intraperitoneal chemotherapy in patients with peritoneal carcinomatosis: role of heat shock proteins and dissecting effects of hyperthermia. Ann Surg Oncol 20(4): 1105-1113, 2013. PMID: 23456378. DOI: 10.1245/s10434-0122784-6

3 Park SJ, Kim J, Kim SN, Lee EJ, Oh S, Seol A, Lee N, Chang SJ and Kim HS: Practice patterns of surgery for advanced ovarian cancer: analysis from international surveys. Jpn J Clin Oncol 49(2): 137-145, 2019. PMID: 30521037. DOI: 10.1093/ jjco/hyy 175

4 Robella M, Vaira M and De Simone M: Safety and feasibility of pressurized intraperitoneal aerosol chemotherapy (PIPAC) associated with systemic chemotherapy: an innovative approach 
to treat peritoneal carcinomatosis. World J Surg Oncol 14: 128, 2016. PMID: 27125996. DOI: 10.1186/s12957-016-0892-7

5 Kim M, Suh DH, Lee KH, Eom KY, Toftdahl NG, Mirza MR and Kim JW: Major clinical research advances in gynecologic cancer in 2018. J Gynecol Oncol 30(2): e18, 2019. PMID: 30806045. DOI: $10.3802 /$ jgo.2019.30.e18

6 Scheithauer W, Kornek G, Rosen H, Sebesta C, Marcell A, Kwasny W, Karall M and Depisch D: Combined intraperitoneal plus intravenous chemotherapy after curative resection for colonic adenocarcinoma. Eur J Cancer 31A(12): 1981-1986, 1995. PMID: 8562152. DOI: 10.1016/0959-8049(95)00426-2

7 Armstrong DK, Bundy B, Wenzel L, Huang HQ, Baergen R, Lele S, Copeland LJ, Walker JL, Burger RA and Gynecologic Oncology Group: Intraperitoneal cisplatin and paclitaxel in ovarian cancer. N Engl J Med 354(1): 34-43, 2006. PMID: 16394300. DOI: 10.1056/NEJMoa052985

8 van Driel WJ, Koole SN, Sikorska K, Schagen van Leeuwen JH, Schreuder HWR, Hermans RHM, de Hingh IHJT, van der Velden J, Arts HJ, Massuger LFAG, Aalbers AGJ, Verwaal VJ, Kieffer JM, Van de Vijver KK, van Tinteren H, Aaronson NK and Sonke GS: Hyperthermic intraperitoneal chemotherapy in ovarian cancer. N Engl J Med 378(3): 230-240, 2018. PMID: 29342393. DOI: 10.1056/NEJMoa1708618

9 Wang Y, Ren F, Chen P, Liu S, Song Z and Ma X: Effects of CytoReductive surgery plus hyperthermic IntraPEritoneal chemotherapy (HIPEC) versus CytoReductive surgery for ovarian cancer patients: A systematic review and meta-analysis. Eur J Surg Oncol 45(3): 301-309, 2019. PMID: 30786961. DOI: $10.1016 /$ j.ejso 2018.10 .528

10 Göhler D, Khosrawipour V, Khosrawipour T, Diaz-Carballo D, Falkenstein TA, Zieren J, Stintz M and Giger-Pabst U: Technical description of the microinjection pump (MIP $\left.{ }^{\circledR}\right)$ and granulometric characterization of the aerosol applied for pressurized intraperitoneal aerosol chemotherapy (PIPAC). Surg Endosc 31(4): 1778-1784, 2017. PMID: 27631320. DOI: 10.1007/s00464-016-5174-5

11 Blanco A, Giger-Pabst U, Solass W, Zieren J and Reymond MA: Renal and hepatic toxicities after pressurized intraperitoneal aerosol chemotherapy (PIPAC). Ann Surg Oncol 20(7): 23112316, 2013. PMID: 23377563. DOI: 10.1245/s10434-012-2840-2

12 Tempfer CB, Rezniczek GA, Ende P, Solass W and Reymond MA: Pressurized intraperitoneal aerosol chemotherapy with cisplatin and doxorubicin in women with peritoneal carcinomatosis: a cohort study. Anticancer Res 35(12): 67236729, 2015. PMID: 26637888. DOI: 10.1055/s-0035-1560004

13 Tempfer CB, Winnekendonk G, Solass W, Horvat R, Giger-Pabst U, Zieren J, Rezniczek GA and Reymond MA: Pressurized intraperitoneal aerosol chemotherapy in women with recurrent ovarian cancer: A phase 2 study. Gynecol Oncol 137(2): 223228, 2015. PMID: 25701703. DOI: 10.1016/j.ygyno.2015.02.009

14 Struller F, Horvath P, Solass W, Weinreich FJ, Strumberg D, Kokkalis MK, Fischer I, Meisner C, Königsrainer A and Reymond MA: Pressurized intraperitoneal aerosol chemotherapy with low-dose cisplatin and doxorubicin (PIPAC C/D) in patients with gastric cancer and peritoneal metastasis: a phase II study. Ther Adv Med Oncol 11: 1758835919846402, 2019. PMID: 31205501. DOI: $10.1177 / 1758835919846402$

15 Pestieau SR, Stuart OA, Chang D, Jacquet P and Sugarbaker PH: Pharmacokinetics of intraperitoneal gemcitabine in a rat model. Tumori 84(6): 706-711, 1998. PMID: 10080682.
16 Pestieau SR, Belliveau JF, Griffin H, Stuart OA and Sugarbaker PH: Pharmacokinetics of intraperitoneal oxaliplatin: experimental studies. J Surg Oncol 76(2): 106-114, 2001. PMID: 11223836. DOI: 10.1002/1096-9098(200102)76:2<106::aid-jso 1020>3.0.co;2-e

17 Glehen O, Stuart OA, Mohamed F and Sugarbaker PH: Hyperthermia modifies pharmacokinetics and tissue distribution of intraperitoneal melphalan in a rat model. Cancer Chemother Pharmacol 54(1): 79-84, 2004. PMID: 15048586. DOI: 10.1007/s00280-004-0779-0

18 Jacquet P, Averbach A, Stuart OA, Chang D and Sugarbaker PH: Hyperthermic intraperitoneal doxorubicin: pharmacokinetics, metabolism, and tissue distribution in a rat model. Cancer Chemother Pharmacol 41(2): 147-154, 1998. PMID: 9443628. DOI: $10.1007 / \mathrm{s} 002800050721$

19 Bendavid Y, Leblond FA and Dubé P: A study of the effect of temperature on the pharmacokinetic profile of raltitrexed administered by intraperitoneal route in the rat. Med Sci Monit 11(1): BR1-BR5, 2005. PMID: 15614183.

20 Zeamari S, Floot B, van der Vange $\mathrm{N}$ and Stewart FA: Pharmacokinetics and pharmacodynamics of cisplatin after intraoperative hyperthermic intraperitoneal chemoperfusion (HIPEC). Anticancer Res 23(2B): 1643-1648, 2003. PMID: 12820435.

21 Klaver YL, Hendriks T, Lomme RM, Rutten HJ, Bleichrodt RP and de Hingh IH: Intraoperative hyperthermic intraperitoneal chemotherapy after cytoreductive surgery for peritoneal carcinomatosis in an experimental model. Br J Surg 97(12): 1874-1880, 2010. PMID: 20806291. DOI: 10.1002/bjs.7249

22 Pelz JO, Doerfer J, Dimmler A, Hohenberger W and Meyer T: Histological response of peritoneal carcinomatosis after hyperthermic intraperitoneal chemoperfusion (HIPEC) in experimental investigations. BMC Cancer 6: 162, 2006. PMID: 16792796. DOI: 10.1186/1471-2407-6-162

23 Pelz JO, Doerfer J, Hohenberger W and Meyer T: A new survival model for hyperthermic intraperitoneal chemotherapy (HIPEC) in tumor-bearing rats in the treatment of peritoneal carcinomatosis. BMC Cancer 5: 56, 2005. PMID: 15924622. DOI: $10.1186 / 1471-2407-5-56$

24 Aarts F, Bleichrodt RP, de Man B, Lomme R, Boerman OC and Hendriks T: The effects of adjuvant experimental radioimmunotherapy and hyperthermic intraperitoneal chemotherapy on intestinal and abdominal healing after cytoreductive surgery for peritoneal carcinomatosis in the rat. Ann Surg Oncol 15(11): 3299-3307, 2008. PMID: 18712445 . DOI: $10.1245 / \mathrm{s} 10434-008-0070-4$

25 Aarts F, Hendriks T, Boerman OC, Koppe MJ, Oyen WJ and Bleichrodt RP: A comparison between radioimmunotherapy and hyperthermic intraperitoneal chemotherapy for the treatment of peritoneal carcinomatosis of colonic origin in rats. Ann Surg Oncol 14(11): 3274-3282, 2007. PMID: 17653591. DOI: 10.1245/s10434-007-9509-2

26 Bouquet W, Ceelen W, Adriaens E, Almeida A, Quinten T, De Vos F, Pattyn P, Peeters M, Remon JP and Vervaet C: In vivo toxicity and bioavailability of Taxol and a paclitaxel/betacyclodextrin formulation in a rat model during HIPEC. Ann Surg Oncol 17(9): 2510-2517, 2010. PMID: 20339948. DOI: 10.1245/s10434-010-1028-x

27 Raue W, Kilian M, Braumann C, Atanassow V, Makareinis A, Caldenas S, Schwenk W and Hartmann J: Multimodal approach for treatment of peritoneal surface malignancies in a tumourbearing rat model. Int J Colorectal Dis 25(2): 245-250, 2010. PMID: 19902227. DOI: 10.1007/s00384-009-0819-7 
28 Facy O, Radais F, Ladoire S, Delroeux D, Tixier H, Ghiringhelli F, Rat P, Chauffert B and Ortega-Deballon P: Comparison of hyperthermia and adrenaline to enhance the intratumoral accumulation of cisplatin in a murine model of peritoneal carcinomatosis. J Exp Clin Cancer Res 30: 4, 2011. PMID: 21214912. DOI: $10.1186 / 1756-9966-30-4$

29 Aghayeva A, Benlice C, Bilgin IA, Atukeren P, Dogusoy G, Demir F, Atasoy D and Baca B: The effects of hyperthermic intraperitoneal chemoperfusion on colonic anastomosis: an experimental study in a rat model. Tumori 103(3): 307-313, 2017. PMID: 28291907. DOI: 10.5301/tj.5000610

30 Bespalov VG, Kireeva GS, Belyaeva OA, Kalinin OE, Senchik KY, Stukov AN, Gafton GI, Guseynov KD and Belyaev AM: Both heat and new chemotherapeutic drug dioxadet in hyperthermic intraperitoneal chemoperfusion improved survival in rat ovarian cancer model. J Surg Oncol 113(4): 438-442, 2016. PMID: 26710749. DOI: 10.1002/jso.24140

31 Verhulst J: Effects of bevacizumab and hyperthermia in a rodent model of hyperthermic intraperitoneal chemotherapy (HIPEC). Int J Hyperthermia 29(1): 62-70, 2013. PMID: 23311379. DOI: $10.3109 / 02656736.2012 .753738$

32 Padilla-Valverde D, Sanchez-Garcia S, García-Santos E, MarcoteIbañez C, Molina-Robles M, Martín-Fernández J and VillarejoCampos P: Usefulness of thermographic analysis to control temperature homogeneity in the development and implementation of a closed recirculating $\mathrm{CO}_{2}$ chemohyperthermia model. Int $\mathrm{J}$ Hyperthermia 33(2): 220-226, 2017. PMID: 27633094. DOI: 10.1080/02656736.2016.1237679

33 De Smet L, Colin P, Ceelen W, Bracke M, Van Bocxlaer J, Remon JP and Vervaet C: Development of a nanocrystalline Paclitaxel formulation for HIPEC treatment. Pharm Res 29(9): 2398-2406, 2012. PMID: 22555379. DOI: 10.1007/s11095-012$0765-\mathrm{x}$

34 Miailhe G, Arfi A, Mirshahi M, Eveno C, Pocard M and Touboul C: A new animal model for hyperthermic intraperitoneal chemotherapy (HIPEC) in tumor-bearing mice in the treatment of peritoneal carcinomatosis of ovarian origin. J Visc Surg 155(3): 183-189, 2018. PMID: 29108718. DOI: 10.1016/j.jviscsurg.2017. 10.008

35 Van de Sande L, Willaert W, Cosyns S, De Clercq K, Shariati $\mathrm{M}$, Remaut $\mathrm{K}$ and Ceelen W: Establishment of a rat ovarian peritoneal metastasis model to study pressurized intraperitoneal aerosol chemotherapy (PIPAC). BMC Cancer 19(1): 424, 2019. PMID: 31064330. DOI: 10.1186/s12885-019-5658-5

36 Solass W, Herbette A, Schwarz T, Hetzel A, Sun JS, Dutreix M and Reymond MA: Therapeutic approach of human peritoneal carcinomatosis with Dbait in combination with capnoperitoneum: proof of concept. Surg Endosc 26(3): 847852, 2012. PMID: 22042585. DOI: 10.1007/s00464-011-1964-y

37 Facy O, Al Samman S, Magnin G, Ghiringhelli F, Ladoire S, Chauffert B, Rat P and Ortega-Deballon P: High pressure enhances the effect of hyperthermia in intraperitoneal chemotherapy with oxaliplatin: an experimental study. Ann Surg 256(6): 1084-1088, 2012. PMID: 22634898. DOI: 10.1097/SLA.0b013e3182582b38
38 Michalakis J, Georgatos SD, de Bree E, Polioudaki H, Romanos J, Georgoulias V, Tsiftsis DD and Theodoropoulos PA: Shortterm exposure of cancer cells to micromolar doses of paclitaxel, with or without hyperthermia, induces long-term inhibition of cell proliferation and cell death in vitro. Ann Surg Oncol 14(3): 1220-1228, 2007. PMID: 17206477. DOI: 10.1245/s10434-0069305-4

39 Jung do H, Son SY, Oo AM, Park YS, Shin DJ, Ahn SH, Park do $\mathrm{J}$ and Kim HH: Feasibility of hyperthermic pressurized intraperitoneal aerosol chemotherapy in a porcine model. Surg Endosc 30(10): 4258-4264, 2016. PMID: 26715024. DOI: 10.1007/s00464-015-4738-0

40 Solass W, Kerb R, Mürdter T, Giger-Pabst U, Strumberg D, Tempfer C, Zieren J, Schwab $M$ and Reymond MA: Intraperitoneal chemotherapy of peritoneal carcinomatosis using pressurized aerosol as an alternative to liquid solution: first evidence for efficacy. Ann Surg Oncol 21(2): 553-559, 2014. PMID: 24006094. DOI: 10.1245/s10434-013-3213-1

41 Mashimo T, Takizawa A, Kobayashi J, Kunihiro Y, Yoshimi K, Ishida S, Tanabe K, Yanagi A, Tachibana A, Hirose J, Yomoda J, Morimoto S, Kuramoto T, Voigt B, Watanabe T, Hiai H, Tateno C, Komatsu $\mathrm{K}$ and Serikawa T: Generation and characterization of severe combined immunodeficiency rats. Cell Rep 2(3): 685-694, 2012. PMID: 22981234. DOI: 10.1016/ j.celrep.2012.08.009

42 Azaïs H, Queniat G, Bonner C, Kerdraon O, Tardivel M, Jetpisbayeva G, Frochot C, Betrouni N, Collinet P and Mordon S: Fischer 344 Rat: A preclinical model for epithelial ovarian cancer folate-targeted therapy. Int J Gynecol Cancer 25(7): 11941200, 2015. PMID: 26244757. DOI: 10.1097/IGC.0000000 000000497

43 Khosrawipour V, Khosrawipour T, Falkenstein TA, DiazCarballo D, Förster E, Osma A, Adamietz IA, Zieren J and Fakhrian K: Evaluating the effect of Micropump $\subset$ position, internal pressure and doxorubicin dosage on efficacy of pressurized intra-peritoneal aerosol chemotherapy (PIPAC) in an ex vivo model. Anticancer Res 36(9): 4595-4600, 2016. PMID: 27630300. DOI: 10.21873/anticanres.11008

44 Khosrawipour V, Khosrawipour T, Diaz-Carballo D, Förster E, Zieren $\mathrm{J}$ and Giger-Pabst $\mathrm{U}$ : Exploring the spatial drug distribution pattern of pressurized intraperitoneal aerosol chemotherapy (PIPAC). Ann Surg Oncol 23(4): 1220-1224, 2016. PMID: 26553440. DOI: 10.1245/s10434-015-4954-9

45 Nair $A B$ and Jacob S: A simple practice guide for dose conversion between animals and human. J Basic Clin Pharm 7(2): 27-31, 2016. PMID: 27057123. DOI: 10.4103/09760105.177703 